Адрес статьи / To link this article: http://cat.ifmo.ru/ru/2017/v2-i3/116

\title{
Гуманитарные ориентиры техногенной среды
}

\author{
А.А. Никонова \\ Санкт-Петербургский государственный университет, Россия \\ museumbox@yandex.ru
}

\begin{abstract}
Аннотация: в статье рассматриваются основные особенности техногенной среды и ее влияние на развитие культуры и институтов памяти. Человек, становясь творцом нового типа искусственного мира, сам изменяется под его воздействием, а техносфера требует от человека приспособления к новой реальности. Изменение ценностных координат человека влияет на культурные институции, особенно на институты памяти (музеи, архивы, библиотеки). Наследие прошлого не является больше социальной ценностью, а становится одной из сфер «потребления». Меняется само понятие коммуникации для музея. Музей «существует» одновременно в реальном и виртуальном пространстве. Мы наблюдаем разрыв между физическим пространством человека и пространством его общения. Посетитель становится пассивным участником музейной коммуникации. Избежать негативных последствий возможно при ином понимании правил визуальной культуры и изучении моделей формирования музейной потребности у посетителя.
\end{abstract}

Ключевые слова: техносфера, технообраз, культурные ценности, культура потребления, новые медиа, музей, музейный предмет, посетитель, визуальная культура.

Изменение основных характеристик современной цивилизации связано с формированием техногенной среды (техносферы), основной особенностью которой является постоянная смена ее внутренних оснований, или генерирование новых образцов, идей, концепций. В то же время, культурная компонента техносферы опосредована генотипом социального поведения и наличием новых смысловых ценностей жизни социума, что оказывает заметное влияние на характер взаимодействия природной среды и человеческого сообщества. Именно техносфера сегодня становится одним из условий самоидентификации общества, когда общество узнает себя в новых характеристиках самой техносферы. Такие достижения цивилизации, как мобильная связь, городское метро, небоскребы, бесконечный поток транспорта, электронные формы продаж товаров давно уже стали не только техническим и эстетическим образом современности, но и устойчивым выражением базовых ценностей жизни людей западной цивилизации. Изменения произошли и в гуманитарной среде, они настолько существенны, что многие исследователи говорят о кризисе современной культуры $[1,2]$. Так, например, мы наблюдаем сегодня доминирование нигилизма по отношению ко всегда существовавшему принципу плюрализма, когда отсутствие устойчивых культурных координат способствует провозглашению абсолютной свободы от любых ограничений в потреблении благ и самореализации человека. Одновременно отрицаются все формы самоограничения или принцип аскетизма, исторически свойственный православной культуре. Присущая экономической модели общества ненадежность долгосрочного 
планирования переносится на всю жизнь человека, а выполнение общественных обязанностей, следование моральному долгу подменяются достижениями в карьере и реализацией новых форм социального успеха. Однако традиционно духовная, художественная и материальная культура опирались на опыт и знания прошлых поколений, на память о достижениях предшественников, на актуализацию культурного наследия, поэтому данная пространственно-временная сфера человеческого существования имела сакральное значение.

Сегодня психологи впервые отмечают появление нового поколения молодых людей, для которых опыт предшествующих поколений не является опорой для самоидентификации, они самостоятельно осваивают реальность настоящего и не ощущают ущербности в потере базовых ценностей [3]. Такую уверенность новому поколения дает возможность быстрого освоения современных технологий, которые «насыщают» жизнь человека иллюзией полноты и ценности существования. В техногенной среде изменилось разделение на сакральное и повседневное пространство культуры, оно исчезло. Сформировалась новая культура - «культура потребления». Возникает уникальная ситуация противоречивого влияния техносферы на жизнь человека. С одной стороны, создаются комфортные условия для существования и удовлетворения всех потребностей человека, с другой - изменяются под воздействием новых техносферных условий биосфера и социальные процессы, но, главное, ценностные и гуманистические ориентиры человека. Человек, становясь творцом нового типа искусственного мира, сам в значительной мере изменяется под его воздействием, а техносфера начинает диктовать ему свои требования и требует от человека приспособления к новой техногенной реальности. Поэтому с развитием новых медиа, на смену индивидуальному «Я», приходит «мультиличность», характеризующаяся множеством ролей и вариантов идентичности [4].

Следует заметить, что наиболее важным компонентом в системе ценностных приоритетов техногенного общества является именно идеал автономии личности, основанный на силовом (властном) преобразовании внешнего для индивида природного и социального мира, некой новой картины мира [5]. Однако автономность личности весьма условна. Независимость от других людей, оборачивается более жесткой зависимостью от новых информационных технологий, моделирующих иные коммуникативные каналы подчинения. Изменение ценностных координат человека влияет на культурные институции, особенно на институты памяти (музеи, архивы, библиотеки). Наследие прошлого, как культурная ценность, которая формирует гуманистические характеристики человека, не является больше социальной ценностью, а становится одной из сфер «потребления». Казалось бы, что в этом нет ничего страшного, поскольку результаты созидательной деятельности в материальном, духовном и художественном мире создаются для использования человеком, следовательно, для его «потребления». Суть произошедшего изменения в том, что меняется соотношение между потреблением и созиданием для каждого отдельного человека. В современном обществе возникает особая потребительская шкала, по которой оценивается статусность и успешность человека, а созидательная и творческая деятельность оценивается только опосредованно к данной потребительской шкале.

Основным негативным фактором следует назвать перенесение «потребительской шкалы» оценивания на результаты деятельности культурных институтов. Необходимо подчеркнуть, что определение негативных процессов, например в музее, затрудненно тем, что активное использование визуальных и информационных технологий создает новый образ музейного предмета - «технообраз», модель восприятия которого уже освоена человеком в повседневных практиках. Новый технообраз не только привычен и понятен зрителю, но становится для него маркером всего нового и современного, а музейные сотрудники стремятся создать в экспозиционном коммуникативном пространстве эффект присутствия и сопричастности. Такое воздействие на эмоции посетителя возможно за счет особого свойства современных медиатехнологий, а именно иммерсивности. В этом контексте развиваются новые виды художественной деятельности, использующие технические средства визуальных медиа, при помощи которых художники пытаются восстановить видимый мир реальности. Здесь уместно было бы вспомнить замечательное исследование Станислава Лема «Сумма технологии», в котором он вводит в оборот термин «фантоматика», как обозначение конечного «движения от натуральных образов к сплошному визуальному ландшафту искусственного происхождения» [6]. По определению Владимира Шкуратова, это процесс непрерывного «улучшения» и «обогащения» натуральной оптики, в котором можно представить момент, когда инициатива в распределении и

Культура и технологии, Том 2, № 2-3 
нормативизации чувственного материала перейдет к информационно-визуальным устройствам. Сегменты информационных и визуальных технологий пересекаются, регулируются не только разделением «вымысла» и «действительности», но и внутренними механизмами масс-медиа. «Фантоматические машины», о которых писал польский фантаст, уже изобретены это оборудование компьютерной виртуалистики. Они пока не способны заменить реальный пейзаж вокруг нас тотальным искусственным зрелищем, но стремятся к этому. Такое можно предположить только в случае, если масса экранов сольется в сплошной экранированный мир (с возможным исчезновением традиционного экрана) [7].

Еще одним способом влияния на адресата следует назвать использование существующих у него базовых или фоновых знаний при представлении новой информации (фрейминг). Визуальные фреймы, транслируемые современными медиа, эстетизируют такие ценностные элементы мира, как богатство, здоровье, культ тела, красоты, успеха, мобильности и прогресса. Такие визуальные образы не эфемерны, сила их воздействия велика, поскольку они встраиваются в механизм потребления человека [8]. Возникает новая эстетика, в которой не может быть страданий, болезни, скуки, разочарований, смерти и грязи. Не вписывается в новую эстетику и музей, хранящий фрагментарные остатки пыльных предметов прошлого, потерявших свою былую утилитарность и привлекательность. Патина времени подлинного музейного предмета в новой эстетике техносреды становиться устойчивой метафорой смерти. Эстетизация повседневности отражается на экспозиционно-выставочных методах, в которых также доминирует стремление к эстетизации и подмене реальности «вычищенной» гиперреальностью.

Таким образом, в современном информационном обществе в центре внимания оказывается уже не вещь, ее культурные и социальные ценности (для музея - это подлинный музейный предмет), a ее образ (вернее, технообраз). Одним из примеров такой подмены является использование цифрового изображения предмета в увеличенном масштабе рядом с витриной, в котором находится экспонат (часы «Павлин» в Эрмитаже). Визуальный образ цифрового изображения, его масштаб и детализация притягивают взгляд посетителя, особенно ребенка. Подлинный шедевр русских мастеров, требующий терпения и сосредоточенности для изучения и понимания остается вне поля «видения» и становится фоном для визуального образа. В этом случае мы наблюдаем как антиномия реального и фигурального обозначает альтернативу актуального и виртуального. Новая технология захватывает не только материальный мир, но и духовный, что отражается и в музейной практике, когда разрушаются границы между медиа и сообщением, между символическим и материальным, а медиасообщения распространяются в качестве товаров. Но визуальная реальность, являясь продуктом культурного конструирования, подлежит «прочтению» как и любой вербальный текст.

Принципиальная разница данного прочтения заключается в том, что визуальные образы предоставляют нам более широкий доступ к множественности человеческого опыта и человеческого поведения, создавая иллюзию открытости. В то же время обилие информации, ее разнообразие не является гарантом для адекватного восприятия и осмысления. Следовательно, важной проблемой сегодня становиться продуцирование нового знания у посетителя музея, который чаще всего не обладает достаточным опытом и необходимым контентом для восприятия информационного поля музейного предмета или подлинной исторической информацией о музейном предмете [9]. Подтверждается это одним из законов информационной экологии — для оптимизации восприятия получаемой информации необходимы не только настроенность на восприятие и ощущение поступающей информации, но и информационный опыт, образованность. Можно согласиться с тем, что визуальная условность всегда существовала в музейных экспозициях, но она зримо отличалась от подлинных предметов и не мешала восприятию исторической информации посетителем.

Однако появление компьютерных имитационных моделей, первоначально с целью получения научных данных, став массовым и визуально доминирующим, значительно снизило гносеологический характер музейной экспозиции. Поэтому потребность в производстве нового знания не восполняется новыми формами актуализации наследия. Так большая часть визуальной и текстовой информации размещенная в интернет-каталогах музейных коллекций настолько скудна и затруднена для дальнейшего использования, что становится бессмысленной. Повседневная жизнь современного человека перегружена визуальными образами медиатехнологий и появление еще одного (музейного) автоматически дополняется к уже сформированным познавательным

International Culture \& Technology Studies, Vol. 2, No. 2-3 
моделям. Результатом такого «скольжения» по поверхности объективной реальности становится «переформатирование» традиционной практики восприятия феноменов прошлого и перенос образов из сакральной, аксиологической и образовательной сферы в сферу развлечения, ролевых компьютерных игр или специальных программ. Проблема заключается в том, что сегодня мы не имеем универсального метода для глубинного анализа визуальных образов. Исследователи отмечают «ограниченность нашей способности говорить об образах современного мира, принципиально медийных, сверхскоростных и ускользающих» [10]. Меняется само понятие коммуникативного пространства для музея. Музей «существует» одновременно в реальном и виртуальном пространстве. Какое из них значимо для посетителя, какое для музейного сообщества - вопрос остается открытым и не исследованным. Это дает основание говорить о свертывании расстояний, в определенном смысле об их «смерти». Поскольку сегодня информационновизуальные технологии меняют восприятие человеком содержания историко-культурной информации, то переход из реального взаимодействия в виртуальное нарушает нравственные и этические нормы межсубъектной коммуникации.

Сознание современного посетителя характеризуют: сиюминутность смыслов, недолговечных знаков, изменивший ритм времени и содержание информации. Изменение количества информации благодаря компьютеризации повлияло на уровень образовательной функции музеев - большой поток информации, представленный линейно сегодня не воспринимается посетителем, он не запоминается. Мы наблюдаем разрыв между физическим пространством человека и пространством его общения. И современные музеи всё чаще сталкиваются с равнодушием посетителей. Полифония экспонатов в экспозиции не всегда способствует концентрации внимания у посетителя. У многих посетителей (или большинства?) итог составляют поверхностные впечатления, общие воспоминания об экспонатах (с выделением 2-3 раритетов) и малый объем вербальной информации. Посетитель становится пассивным участником музейного пространства. Это может повлечь за собой в дальнейшем полное изменение концепции музеев в плане подачи информации (включение электронных технологий, особенно в формате 3D или 4D будет основным). Пресыщение, утомляемость, фрагментарность информационного потока способствует возникновению дополнительного информационного шума в музейной среде. Остро возникает проблема экологии знания в музее. Нужно искать новые формы диалога между субъектами, ориентированные на выработку «общего взгляда на вещи», учитывающие доминирование не только визуального канала восприятия. Существующая проблема перехода от пассивно-информационной формы подачи материала в экспозиции к аттрактивной и информационной форме не обязательно должна быть ограничена применением медиатехнологий, а может использовать особенности межличностной передачи информации. Подтверждением обозначенных трансгрессий в деятельности институтов памяти (на примере музея) являются две тенденции:

1. Размывание институциональных границ музея как культурной формы. Поскольку музеем сегодня может быть названо любая организация, оказывающая «культурноразвлекательные» услуги;

Наиболее ярким примером могут служить интерактивные музеи или эксплориумы. В таких научно-исследовательских учреждениях нет коллекций подлинных предметов-памятников. Экспозиции таких музеев используют модели, копии, интерактивные панели, предназначенные только для трансляции информации о предмете. Следовательно, они не выполняют одну из основных функций музея - документирования. Тем не менее, популярность эксплориумов растет и посетитель не задумывается над причинами такого успеха. Одним из популярных проектов интерактивного музея можно назвать открытый в Москве в 2012 году Еврейский музей и центр толерантности. Большую часть экспозиции занимают аудиовизуальные экспонаты и мультимедийные экраны, 4D-кинотеатр, сенсорные панели и голографические инсталляции, раскрывающие историю еврейского народа [11].

2. Процесс интеграции институтов памяти, когда в целях доступности, открытости и организации досуга институты памяти начинают расширять свои функции и сферы деятельности. Они пытаются работать на посетителя, причем порой совершенно не свойственными для их сущности методами. Происходит размывание границ институтов, приводящее к их интеграции. 
Следовательно, техногенная среда создает своеобразную завесу между человеком и миром, управляет видимым и невидимым, определяет границы и смыслы репрезентации в публичном пространстве или отказывает ему в этом праве. Современные способы медиапотребления моделируют типовые ситуации и новые роли и варианты поведения зрителя / потребителя и закрепляют степень его успешности в обществе потребления. Электронные технологии меняют приоритеты в традиционных формах восприятия музейного предмета.

Сегодня музейная экспозиция как открытая система, благодаря активному внедрению электронных технологий, теряют свой фигуральный смысл. Утративший целостность, стабильность и определенность собственных границ музейный предмет, преобразованный в новый виртуальный объект, превращается в объект манипуляции и иногда бессмысленной трансформации множеством субъектов, когда уравниваются права посетителя и музейного специалиста в интерпретации историко-культурного контента. Открытость профессиональных интерпретаций подменяется мультивоздействием и поведенческим полилогом пользователя с компьютерным изображением. Традиционные музеи, имеющие линейно выстроенные экспозиции начинают трансформировать свое смысловое пространство в сторону нелинейности, гипертекстуальности. Так создаются условия для самостоятельного передвижения посетителя, не желающего следовать за экскурсоводом и выстраивающего свой индивидуальный маршрут «прочтения» экспозиционного текста по аналогии с гипертекстуальным виртуальным пространством, по привычной для него системе гиперссылок. Данная матрица познавательного опыта кардинально отличается от прежних практик индивидуального посещения музея тем, что в гипертекстуальном виртуальном пространстве нарушены иерархии познавательных структур, здесь можно «погружаться» для перекомпозиции фрагментов и переживаний. В таком пространстве исчезает подлинность музейного предмета как транслятора базовых ценностей культуры. Следовательно, меняется результат восприятия музейного предмета. Его реальный, физический образ как самоценность становится вторичной, перекрываемой визуальным технообразом. Смыслы входят в конфликт и запоминаются быстро и надолго яркая визуальная информация, без связи со сложным контекстом. Избежать негативных последствий возможно при ином понимании доминат музейной культуры, формировании правил визуальной культуры на основе исследовательских результатов изучения моделей формирования музейной потребности у посетителя.

Исследование осуществлено при поддержке гранта РГНФ № 13-03-00449.

\section{Литература}

[1] Кастельс М. Информационная эпоха: экономика, общество и культура / Пер. с англ.; под науч. ред. О.И. Шкаратана. М., 2000. 420 с.

[2] Тоффлер Э. Шок будущего. М., 2003. 380 c.

[3] Пищик В. И. Психологические особенности поколений в культурном контексте // Научно-методический электронный журнал «Концепт». 2015.№ 4 (апрель). C.1-5. URL: http://e-koncept.ru/2015/15089.htm (дата обращения: 12.06.2017).

[4] Попкова Н.В. Основные противоречия техносферы // Философия и общество. Выпуск №3(40). 2005. URL: http://www.socionauki.ru/journal/articles/126660/ (дата обращения: 19.06.2017).

[5] Сергеев С.Ф. Глобальные техногенные среды в эволюции человеческой цивилизации // Вестник Московского университета имени С. Ю. Витте. Серия 1: Экономика и управление. 2013. №1. С.80-86.

[6] Лем С. Сумма технологии. URL: http://e-libra.ru/read/342260-summa-tehnologii.html/ (дата обращения: 22.05.2017).

[7] Шкуратов В. А. Искусство экономной смерти. Сотворение видеомира. Ростов Н/Д: «Наррадигма». 2006. 400 c. URL: http://propagandahistory.ru/books/Vladimir-SHkuratov_Iskusstvo-ekonomnoy-smerti--Sotvorenie-videomira/ (дата обращения: 15.06.2017).

[8] Мясникова Л.А., Дроздова А.В., Архипова Ю.В. Визуальная презентация повседневности в современном медиаобществе // Теория и практика общественного развития. 2014 №19. С. 168-172.

[9] Никонова А.A. Метаморфозы актуализации музейного предмета как исторического источника // Роль музеев в информационном обеспечении исторической науки: сборник статей / Авт.-сост. Е.А. Воронцова; отв. ред. Л.И. Бородкин, А.Д. Яновский. М.: Этерна, 2015. 752 с. С.263-273.

[10] Шетинина С.Ю. Визуальные медиа в мультимедийной инсталляции // Вестник КемГУКИ. 2016. № 37. C.188-193.

[11]Еврейский музей и центр толерантности. URL: https://www.jewish-museum.ru/ (дата обращения: 12.06.2017).

International Culture \& Technology Studies, Vol. 2, No. 2-3 


\title{
Humanitarian Guidelines for Technological Environment
}

\author{
A.A. Nikonova
}

\author{
Saint Petersburg State University, Russia
}

\begin{abstract}
The article discusses the main features of the technological environment and its impact on the development of culture and memory institutions. A man, becoming a creator of a new type of artificial world, changes under its influence, and the techno-sphere requires adaptation to the new reality. Changing of human value coordinates influences cultural institutions, especially institutions of memory (museums, archives, libraries). The legacy of the past is no longer a social value, and is becoming one of the areas of "consumption". The notion of communicative space of museum also changes. Museum "exists" simultaneously in real and virtual space. We are seeing the gap between physical space and human space of communication. A visitor becomes a passive participant in the museum space. Avoidance of the negative consequences is possible with a different understanding of rules of visual culture and the study of models of the visitors' museum needs.
\end{abstract}

Keywords: techno-sphere, techno-image, cultural values, consumer culture, new media, Museum, museum object, visitor, visual culture.

\section{References}

[1] Kastel's M. Informacionnaja jepoha: jekonomika, obshhestvo i kul'tura / Per. s angl.; pod nauch. red. O.I. Shkaratana. M., 2000. 420 p.

[2] Toffler Je. Shok budushhego. M., 2003. 380 p.

[3] Pishhik V. I. Psihologicheskie osobennosti pokolenij v kul'turnom kontekste // Nauchno-metodicheskij jelektronnyj zhurnal «Koncept». 2015. № 4. Pp. 1-5. Available at: http://e-koncept.ru/2015/15089.htm/ (access date: $12 / 06 / 2017)$

[4] Popkova N.V. Osnovnye protivorechija tehnosfery // Filosofija i obshhestvo. Vypusk №3(40). 2005. Available at: http://www.socionauki.ru/journal/articles/126660/ (access date: 19/06/2017)

[5] Sergeev S.F. Global'nye tehnogennye sredy v jevoljucii chelovecheskoj civilizacii // Vestnik Moskovskogo universiteta imeni S. Ju. Vitte. Serija 1: Jekonomika i upravlenie. 2013. №1. Pp. 80-86.

[6] Lem S. Summa tehnologii. Available at: http://e-libra.ru/read/342260-summa-tehnologii.html (access date: 22/05/2017).

[7] Shkuratov V. A. Iskusstvo jekonomnoj smerti. Sotvorenie videomira. Rostov N/D: «Narradigma». 2006.400 p. Available at: http://propagandahistory.ru/books/Vladimir-SHkuratov_Iskusstvo-ekonomnoy-smerti--Sotvorenie-videomira/ (access date: 15/06/2017).

[8] Mjasnikova L.A., Drozdova A.V., Arhipova Ju.V. Vizual'naja prezentacija povsednevnosti v sovremennom mediaobshhestve // Teorija i praktika obshhestvennogo razvitija. 2014. №19. Pp.168-172.

[9] Nikonova A.A. Metamorfozy aktualizacii muzejnogo predmeta kak istoricheskogo istochnika // Rol' muzeev v informacionnom obespechenii istoricheskoj nauki: sbornik statej / Avt.-sost. E.A. Voroncova; otv. red. L.I. Borodkin, A.D. Janovskij. M.: Jeterna, 2015. 752 p. Pp.263-273.

[10] Shetinina S.Ju. Vizual'nye media v mul'timedijnoj installjacii // Vestnik KemGUKI. 2016. No 37. Pp.188-193.

[11] Evrejskij muzej i centr tolerantnosti. Available at: https://www.jewish-museum.ru/ (access date: 12/06/2017). 